\title{
Narratology and Rhetoric: Scientific Terminology?
}

José Angel García Landa

University of Zaragoza, 1991

Electronic edition 2004

According to the definition of the International Association of Terminology, "Terminology is concerned with the study and use of the system of symbols and linguistic signs employed for human communication in specialised areas of knowledge and activities." Literary studies are such a specialised activity nowadays, and we witness in this field an increasing proliferation of technical terms which some consider to be necessary conceptual equipment, and according to others are nothing but fussy jargon. Do these technical terms give literary studies the status of a science, comparable to that of the physical or natural sciences? I will leave the question open, making only a few observations on the status of technical vocabulary in scientific theories and in philology.

The main difference between the status of knowledge between human sciences like literary criticism and the "hard" sciences would seem to be that in the former there is a continued controversy over fundamental terms and concepts at all levels, while the latter seem to rely on more objective methods and to define their terms in a way which is less open to controversy. The difference would then be one of precision in methodology. Scientific discussions are conducted in a more objective way, and the language of science is more precise and referential than the language of literary studies, which would seem to be under the influence of its object: poetry cannot be studied in a completely scientific way; an amount of invention and ability as a writer is needed to study writing in an adequate way. We should beware of any simple opposition between the status of the disciplines of science and humanistic studies. Since they focus on different objects and they provide different kinds of knowledge, there is not much point in setting one over the other arguing that the knowledge of science is somehow more real or definite. Since there is no possibility of approaching a poem as a chemist or a nuclear physicist, it seems we should be satisfied with the kind of knowledge poets and critics give us in this respect.

But we cannot leave things like this, merely pointing out the differences between both areas of knowledge. Perhaps it is more fruitful to try and see the analogies. Since both science and literary studies try to define methods and a technical 
vocabulary, can we compare the role of methodology and terminology in both?

The resemblances may turn out to be more striking than the differences. Precision of reference seems to be in both cases an ideal which cannot explain the activity of the critic or the scientist. Even in physical science, a technical term has a clear, unambiguous and definite value only insomuch as it is an instrument. This conception leaves aside the more interesting aspect of technical terms, which appears when their ambiguities reappear, when they cease to be well-shaped cubes of meaning and become fuzzy, interconnected, problematic.

H. G. Gadamer wrote to this purpose when comparing the role of method in the human and the physical sciences. His conclusion is that not only the human sciences, but also the physical ones, are basically hermeneutic and exploratory, that is, that they are not ultimately based on a hypothetical scientific method. The real scientific breakthrough comes about when new interpretive hypotheses change our outlook on the data and on the old methods. According to Gadamer, the creative moment of a method is to be found only at its outset, when the method is defined. A method is like a question, which starts from certain presuppositions and opens up the possibility of a limited set of answers. Systematic reliance on the method will not provide radically new knowledge, but only limited answers to the limited question which is the method. However, this limitation of the scope of method should not make us discard all methods as useless drudgery. There is an interpretive moment in all use of a method.

Any use of a method is also an interpretation. This is easy to see if we conceive of interpretation as a translation from the general to the particular, as a concretization and specific application of a given complex of meaning. An analogy can be drawn from the field of law: any law is by definition general, it is designed to subsume an indefinite number of practical cases. But this means that the law does not deal with the case in its concreteness; it selects certain relevant aspects from the case. Deciding on the relationship between a particular event and the law requires interpretation. It is to be noted that the application of the law changes the law to some extent: a definitive sentence sets a precedent which will be used as a guide to further interpretation of the law in future cases. It is clear that the more unforeseen the case, the greater will be the relevance of its interpretation. The greater the distance between the particular case and the general law, the more creative is the interpretive act.

Let us think now of the way technical terms are used in scientific discussion. A piece of research usually works towards a definite aim. It is a discussion which takes place in a very definite context, and following a well established method. The precise meaning of terms is ensured by the use of a standard technical language and by the specific reference to previous research on the topic. The discussion is highly technical, but all throughout there is a section which cannnot be "technical" in this sense of having a precise and unambiguous reference, an area in which, so to speak, method fails. This area is precisely the subject of the research. Method provides an orientation for the problem and a foothold in neighbouring 
phenomena so that we can have an instrument, a way to approach the issue. But using a method also means closing off certain areas from our interrogation. From the moment we use a term in its technical sense, we are transforming it into a tool, and no longer the object of our work. An instance can be Albert Einstein's account of his research on the theory of relativity, which was to change of our conceptions of space and time. The first thing Einstein has to do in order to approach his subject is to discard as vague and insufficiently defined the concepts of "space" and "time". He starts his research from other areas of physics, and the result can be a new conception of space and time. However, space and time are problematic concepts not in se, but only with respect to a given line of inquiry. The use of these concepts can be perfectly unambiguous and unproblematic if they are used as peripheral elements in a treatise on geology, for instance.

Likewise, in physics or natural sciences, scientific laws and methods have a dialectical relationship with the object of study. The end of a method is to lead us to identify and solve a certain class of problems; a scientific law also points out a kind of unity which underlies a set of phenomena.

But a wholly new perspective goes beyond the application of a method or the subsuming of a principle under a law. A wholly new perspective in science consists in developing a new method or discovering a new law. For instance, take the concept of "organic relationship" in biology. Up to the nineteenth century it was used to describe the relationships between different tissues in the living body. However, around the middle of the nineteenth century, the theories of Auguste Comte, Herbert Spencer, George Henry Lewes and others extend the notion of organicism well beyond the limits of biology: it is now used to describe the relationship between the individual and his medium. This new perspective will lead to the notion of ecology, as well as to a rethinking of individuality as a function of a complex psychic and social life. According to Lewes, mind functions in a similar way to organic life: it should not be considered as an isolated center of organisation, but a system of interaction between the organism and its medium. Lewes argued that the conscious, rational part of our minds should not be privileged in our scientific conceptions, since it is only one aspect of that mental dynamism. It is easy to see that this theory opens the way for further inquiry into the unconscious and the social construction of individuality (Freud, Lacan). Scientific development here originates in a metaphor: the image of the social body which goes back at least to Menenius Agrippa. The systematic exploration of this metaphor turned it into a literal expression, enlarging the concept of organicism. It would be interesting to study how this conceptual change came about, but one thing is certain: it was due to the convergence of many developments in social, psychological and biological theory, and not to a deliberate and foreseeable methodological choice.

This indefinite relationship between a method and its application is also present in the field of literary studies. A welldefined method of literary criticism has the awesome aspect of a compilation of civil law--or an abstruse theological treatise. I once heard a fellow student say of Northrop Frye's Anatomy of Criticism: "It all sounds to me like a religion I don't believe in." Frye is certainly a formidable theologian, with his implied circles and phases, mythoi and modes, all 
revolving around an unnamed centre. But I think my friend approached Frye in the wrong way--seeing his work as a practical guide for pigeonholing works of literature into formal genres and thematic subgenres--defining, for instance, Don Quijote as "a degraded romance with anatomical elements, moving from the third phase of romance into the fourth phase of irony". Certainly, if we use Frye's model as a method for the study of literature I think we shall be the poorer. However, reading Anatomy of Criticism gives anyone, I think, an unforeseen perspective on literature which is enriching even if we do not fully share it. I think the technical terms used here by Frye are useful in giving form to his view of literature, but what is illuminating is the vision of the literary field conveyed by the work as a whole. Some of the more famous coiners of critical jargon, such as Frye, or Genette in his Narrative Discourse, do not conceive their theory-making as a blueprint for further research, but as the research itself, inseparable from the perspective provided on specific works.

Critical jargon is not completely new in literary studies. Classical rhetorical analysis, as developed from the Sophists through the Middle Ages and the Renaissance into the eighteenth century, resulted in the proliferation of technicalities defined with ever more microscopic precision; the inventories of tropes and figures must contain thousands of items, among which we could include some far-fetched ones like. We cannot say, however, that this methodical analysis of discourse ever approached a more adequate knowledge of its object while it delved in this pre-established direction. Plato already complained of the proliferation of technical rhetorical terms in Phaedrus. His own approach to the study of discourses is a different one: not from the point of view of formal rhetoric, but from the point of view of moral philosophy. A new intention brings along a new method, and with a new purpose of his own in mind, Plato can discard as useless machinery the rhetorical analysis of the Sophists. We see that adequacy is defined by the aims of literary study at a given time. Rhetorical analysis opens up a horizon of inquiry on the nature of a discourse which must seem narrow when compared with the Platonic one.

In the same way, a formalist approach of our own century like structuralist narratology will seem narrow and mechanical when it is used as a mere device for categorizing and classifying a series of phenomena which are already pre-defined by the theory. The danger is even greater if the definitions are assumed to be final. Can we ever define with precision what is an 'external focalizer', or an 'homodiegetic narrator'? I do not think this is the case: when the moment of application comes, we shall see that our definitions are always insufficient--except in the most uninteresting cases. Even if we wished to construct all-inclusive tables which specified all the problematic cases we find as we go along, we would not have solved the question of method. A method is a starting point, a question which opens up a discussion. But the question cannot be the final answer. Probably, in the case of narratological analysis, our best insights will come when we combine the method with a line of inquiry deriving from another discipline--say, psychoanalysis or deconstruction, a conjunction which illuminates the work in a way no pre-established method can. Our encounter with the work should be unique, a private scientific revolution of our own. 
The use of a method and a precise terminology can teach us to order and develop our perception, to see better; but the method stops short of the truly interpretive moment. According to T. S. Kuhn, "In the metaphorical no less than in the literal use of 'seeing,' interpretation begins where perception ends. The two processes are not the same, and what perception leaves for interpretation to complete depends drastically on the nature and amount of prior experience and training." A method can teach us to perceive things which escape the perception of those who lack a method. It cannot give us the clue for interpretation, since the act of interpretation involves an interaction between the original complex of meaning and the context of the interpreter, including the specific aim of the research. Interpretation involves a perception of practical needs in the interpreter's intellectual context. It is the interpreter's task to find in which way a work or a methodological approach can become relevant and significant for us here and now. I have said both a work and a method, since both should be objects of interpretation, and help illuminate each other through the critic's activity.

I would conclude therefore that technical terms in literary studies share in the general nature of methodology: they will not on the whole contribute to clarify our understanding of literature; rather, they will make it more complex. This is not a defect of the technical approaches, but rather the condition set by the context in which they are used: the increasing specialization and professionalization of literary studies and the broadening horizons of cultural production. The aim of the literary scholar should be to preserve the unity of culture once its variety is acknowledged--to show how in spite of the complexities of modern cultural production, of postmodernist literature and post-structuralist critical theory, understanding is not impossible: that the literary tradition can still be looked at with new eyes, that different perspectives on reality can still translate into each other, that different codes can be used to make sense of an object--which is after all the semiotic definition of meaning. Another way to put it is that the aim of philology as a science is to preserve the possibility of communication within different cultural productions. In this context, terms and concepts cannot remain static, precise and unambiguous forever: instead, we must learn to set them in motion and make them speak through each other.

\section{Works Cited}

Einstein, Albert. Sobre la teoría especial y la teoría general de la relatividad. El significado de la relatividad. Trans. Miguel Paredes Larrucea, Carlos E. Prélat and Albino Arenas Gómez. Barcelona: Planeta, 1985. Trans. of Über die spezielle und die allgemeine Relativitätstheorie (1917) and The Meaning of Relativity (1921). 
Gadamer, Hans-Georg. Verdad y método: Fundamentos de una hermenéutica filosófica. Trans. Ana Agud Aparicio and Rafael de Agapito. Salamanca: Sígueme, 1977. Trans. of Wahrheit und Methode. 1960. 4th ed. Tübingen: Mohr, 1975.

Kuhn, Thomas S. The Structure of Scientific Revolutions. 2nd. ed. Chicago: U of Chicago P, 1970.

Shuttleworth, Sally. George Eliot and Nineteenth-Century Science: The Make-Believe of a Beginning. Cambridge: Cambridge UP, 1984.

(Comunicación presentada en el seminario Susanne Hübner,"Terminología de Uso Común en las Ciencias del Lenguaje, Crítica Literaria y Estudios Socio-Culturales", organizado por el Departamento de filología Inglesa y Alemana de la Universidad de Zaragoza, del 30 de enero al 1 de febrero de 1991) 